\title{
Organ Cross Talk in the Critically Ill: The Heart and Kidney
}

\author{
Robb Kociol $^{\mathrm{a}}$ Joseph Rogers ${ }^{\mathrm{b}} \quad$ Andrew Shaw $^{\mathrm{c}}$ \\ a Division of Cardiology, Department of Medicine, Duke University Hospital, b Duke Clinical Research Institute, and \\ 'Department of Anesthesia, Duke University Medical Center, Durham, N.C., USA
}

\section{Key Words}

Cardiorenal syndrome $\cdot$ Chronic heart failure $\cdot$ Worsening

renal function - Acute decompensated heart failure

\begin{abstract}
Heart failure results in significant morbidity and mortality in the United States. Chronic heart failure is often complicated by renal insufficiency. Further, acute decompensated heart failure is often complicated by worsening renal function or the development of diuretic resistance. Heart failure complicated by renal dysfunction has a significantly worse prognosis. The pathophysiology underlying this so-called cardiorenal syndrome (CRS) is unclear. It likely involves a combination of maladaptive neurohormonal activation and renal homeostatic mechanisms. The treatment (including recombinant B-type natriuretic peptide, ultrafiltration, continuous furosemide infusions and vasopressin antagonists) has thus far been marginally successful at best. Further research into the mechanism and treatment of CRS is required.
\end{abstract}

Copyright $\odot 2009$ S. Karger AG, Basel

\section{Introduction}

Heart failure results in significant morbidity and mortality in the United States. The estimated prevalence is greater than 5 million persons, resulting in over 1 million hospital discharges yearly and costing the health care system in excess of USD 30 billion [1]. Chronic heart failure is often complicated by renal insufficiency. Additionally, treatment of patients admitted to the hospital with acute decompensated heart failure (ADHF) is frequently limited by worsening renal function and diuretic resistance. This so-called cardiorenal syndrome (CRS) identifies a subset of patients with a worse prognosis and one that is more difficult to treat. The purpose of this review is to examine the burden of concomitant heart failure and renal dysfunction, review what is known of the underlying pathophysiology, investigate the various treatment options and discuss areas of active clinical research.

\section{Definition}

There exists no uniform definition of the CRS. Some have simply defined it as combined cardiac and renal dysfunction. Heywood [2] defined the CRS 'as moderate or greater renal dysfunction that exists or develops in a patient with heart failure (either systolic or with preserved systolic function) during treatment'. Recently, a consensus definition for CRS was proposed by Ronco et al. [3]. It delineates acute from chronic CRS and which organ is initially dysfunctional. Type 1 CRS is defined as acute cardiac dysfunction (e.g. ADHF) that results in acute kidney injury (AKI). Type 2 CRS implies chronic heart failure that results in progressive kidney dysfunction. Type 3 CRS reflects acute kidney dysfunction, such as ischemic injury or glomerular disease, which results in an acute cardiac insult such as heart failure or arrhythmia. Type 4

\section{KARGER \\ Fax +4161306 1234 \\ E-Mail karger@karger.ch}

www.karger.com
(C) 2009 S. Karger AG, Basel

0253-5068/09/0274-0311\$26.00/0

Accessible online at:

www.karger.com/bpu
Dr. Andrew Shaw

Department of Anesthesiology

Duke University Medical Center

Durham, NC 27516 (USA)

E-Mail andrew.shaw@duke.edu 
CRS is chronic renal dysfunction resulting in adverse cardiac effects such as coronary artery disease and heart failure. Type 5 CRS is defined as a systemic event which results in concomitant cardiac and renal dysfunction, such as sepsis [3]. This review primarily focuses on type 1 CRS and, to a lesser degree, type 2.

\section{Epidemiology}

Baseline renal insufficiency, or chronic kidney disease, is well established as an independent predictor of poor outcomes among those patients with chronic heart failure as well as those admitted with ADHF. In a retrospective analysis of the Studies of Left Ventricular Dysfunction (SOLVD) prevention and treatment trials, moderate renal insufficiency defined as creatinine clearance $<60 \mathrm{ml} / \mathrm{min}$ was independently associated with a significant increase in all-cause mortality and the composite end point of death or hospitalization for heart failure. This difference remained significant after multivariate adjustment for disease severity and comorbidities [4]. The Candesartan in Heart Failure: Assessment of Reduction in Mortality and Morbidity (CHARM) investigators confirmed these findings. Their analysis revealed that an estimated glomerular filtration rate (GFR) $<60 \mathrm{ml} / \mathrm{min}$ was a strong, independent predictor of all-cause mortality and/or admission for chronic heart failure. Interestingly, the prognostic value of estimated GFR was similar among those with reduced left ventricular ejection fraction and those with preserved systolic function [5]. Finally, Smith et al. [6] performed a meta-analysis of 16 studies evaluating the impact of renal insufficiency on the outcome of heart failure. The 16 studies enrolled over 80,000 patients. The prevalence of any renal dysfunction, defined as serum creatinine $(\mathrm{SCr})>1.0 \mathrm{mg} / \mathrm{dl}$, estimated GFR $<90 \mathrm{ml} / \mathrm{min}$ or cystatin C $>1.03 \mathrm{mg} / \mathrm{dl}$, was $63 \%$. The prevalence of moderate to severe renal dysfunction, i.e. SCr $>1.5 \mathrm{mg} / \mathrm{dl}$, estimated GFR $<53 \mathrm{ml} / \mathrm{min}$ or cystatin $\mathrm{C}>1.55 \mathrm{mg} / \mathrm{dl}$, was $29 \%$. The prevalence of renal dysfunction was higher in hospitalized patients than in outpatients. In this study, more serious renal insufficiency was correlated with an incremental increase in mortality. The investigators reported a 33\% increased risk of mortality for each increase in SCr of $1 \mathrm{mg} / \mathrm{dl}$ (3 studies) and $7 \%$ increased risk of mortality for each decrement in estimated GFR of $10 \mathrm{ml} / \mathrm{min}$ (2 studies). This study also highlighted the variation in methods used to characterize renal dysfunction (SCr, GFR, creatinine clearance, cystatin C) [6].
Investigators have also evaluated the prognostic significance of worsening renal function during inpatient treatment for ADHF. Renal function is dynamic and often changes while patients undergo inpatient treatment for heart failure. It has been variably defined as an increased SCr $>0.3 \mathrm{mg} / \mathrm{dl}$, an increase in $\mathrm{SCr} \geq 0.3 \mathrm{mg} / \mathrm{dl}$ and $\geq 25 \%$ increase in SCr to $\geq 2 \mathrm{mg} / \mathrm{dl}$. Baseline renal insufficiency, uncontrolled hypertension, diabetes mellitus, calcium channel blocker use and high-dose loop diuretics have all been associated with worsening renal function. Among those patients who develop worsening renal function, most studies have shown an increased length of hospital stay and increase in mortality [7-9]. Interestingly, a post hoc analysis of the Evaluation Study of Congestive Heart Failure and Pulmonary Artery Catheterization Effectiveness (ESCAPE) trial failed to show an association between worsening renal function and outcomes, while it did confirm that baseline renal insufficiency was significantly associated with worse outcomes, defined as death or rehospitalization [10].

\section{Pathophysiology}

In a broad sense, the CRS represents a complex interplay of neurohormonal activation which is maladaptive and contributes to progressive renal dysfunction and worsening heart failure. It is well established that the renin angiotensin aldosterone system (RAAS) and sympathetic nervous system (SNS) are both activated in heart failure. The SNS further contributes to increased systemic vascular resistance and stimulates renal renin release via circulating catecholamines and direct neuronal innervation [11]. SNS overactivity may be further enhanced by baroreceptor desensitization [12]. RAAS activation, both by hemodynamic alterations and SNS stimulation, results in the release of angiotensin II, which promotes vasoconstriction, renal glomerular efferent arteriolar vasoconstriction and adverse cardiac remodeling and triggers aldosterone release. Aldosterone enhances salt and water retention in addition to promoting cardiac fibrosis [13]. Finally, nonosmotic release of arginine vasopressin results in vasoconstriction, free water retention and hyponatremia. The natriuretic peptides [atrial natriuretic peptide and B-type natriuretic peptide (BNP)] are the heart's counterregulatory hormones, which in the healthy individual can attenuate activation of the RAAS and SNS. However, their chronic release in heart failure likely renders them ineffective. Renal dysfunction and uncontrolled hypertension also activate 


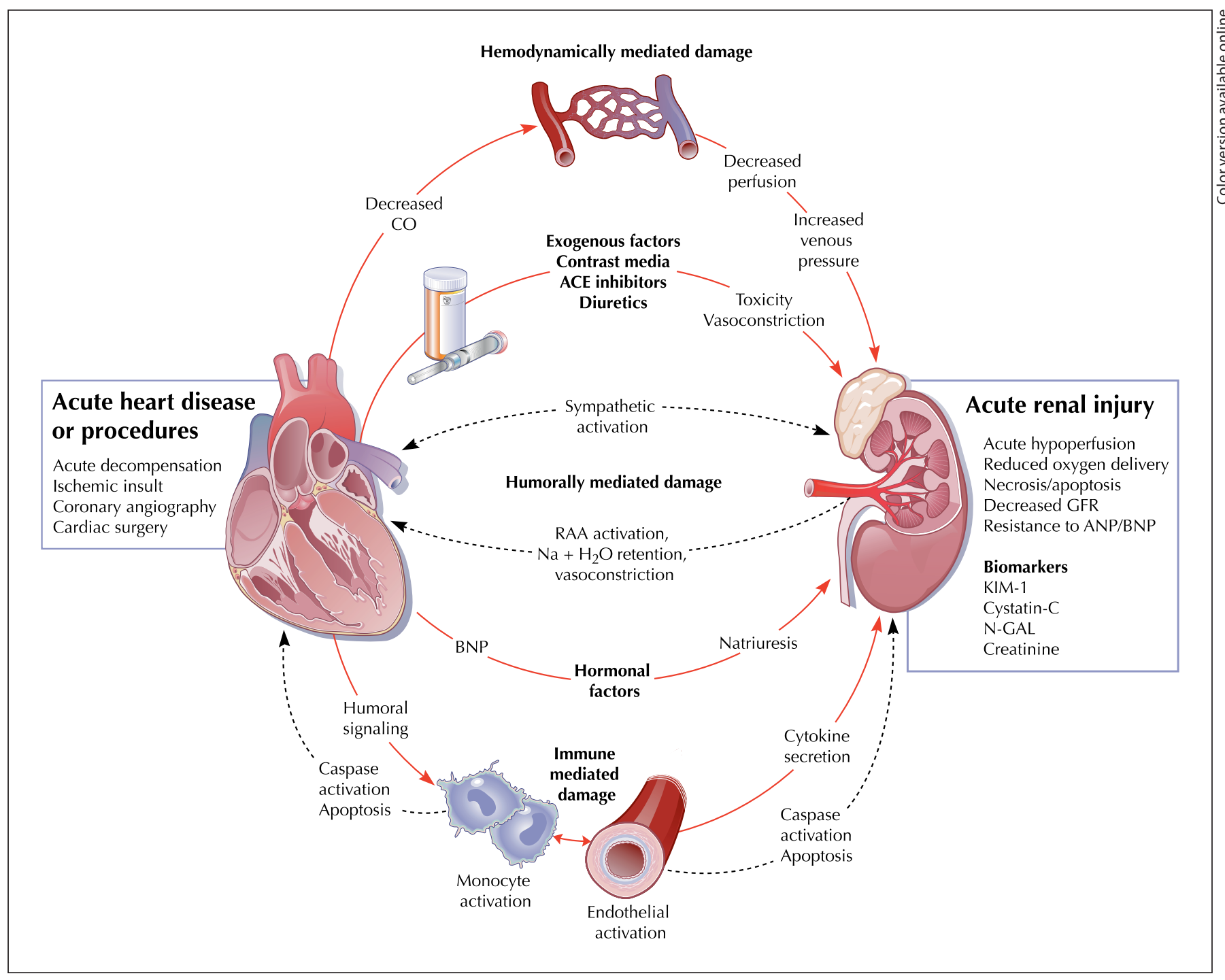

Fig. 1. CRS type 1. Pathophysiological interactions between heart and kidney in type 1 CRS or 'acute CRS' (abrupt worsening of cardiac function, e.g. acute cardiogenic shock or acute decompensation of chronic heart failure) leading to kidney injury. ACE = Angiotensin-converting enzyme; ANP = atrial natriuretic peptide; $\mathrm{CO}$ = cardiac output; KIM = kidney injury molecule; N-GAL = neutrophil gelatinase-associated lipocalin; RAA = renin angiotensin aldosterone. Figure illustration by Rob Flewell. Reprinted from Ronco et al. [3], with permission.

the RAAS, thereby contributing to progressive heart failure [14-17] (fig. 1).

It is tempting to attribute worsening renal function in decompensated heart failure to alterations in central hemodynamics. Intuitively, it would make sense that decreased mean arterial pressure and cardiac output would result in decreased renal perfusion leading to prerenal azotemia and acute tubular necrosis. Indeed, Butler et al. [18] confirmed that left ventricular assist device place- ment rapidly improved renal function in a group of patients with severely impaired cardiac output and renal dysfunction. Other studies, however, have not showed an association between central hemodynamics and worsening renal function. As mentioned above, Forman et al. [7] showed an association between hypertension and worsening renal function. They did not show an association between ejection fraction or hypotension and worsening renal function. Indeed, patients with preserved ejection 
fraction were just as likely to develop worsening renal function [7]. A smaller study by Weinfeld et al. [9], looking at worsening renal function during therapy for advanced heart failure, did not show an association between worsening renal function and cardiac index, systemic vascular resistance or other hemodynamic variables. Interestingly, the only hemodynamic variable found to be associated with worsening renal function in a retrospective analysis of the ESCAPE trial was right atrial pressure [10]. Increased right atrial pressure in ADHF results in peripheral edema and ascites. Investigators at the Cleveland Clinic have utilized a simple transvesical method to measure intra-abdominal pressure and its association with worsening renal function. They found an association between increased intra-abdominal pressure and renal dysfunction and that therapy which improved hemodynamics and decreased intra-abdominal pressure was associated with improved renal function. These findings may help elucidate those factors leading to worsening renal function in ADHF and help explain the subset of patients whose renal function improves with aggressive diuresis [19].

A dysfunctional atrial-renal reflex has also been implicated in cardiorenal dysfunction. Normally, increased volume leading to increased atrial filling pressures results in the release of atrial natriuretic peptide and inhibition of arginine vasopressin, thus resulting in increased renal blood flow and natriuresis. This effect appears to be blunted in the chronically volume overloaded state of heart failure. In addition, there is a blunted response to a further salt load. In response to diuresis, there may, in fact, be a sudden drop in natriuretic peptide levels and increased arginine vasopressin release $[9,14]$.

Given the poor correlation between central hemodynamics, particularly cardiac index and systemic vascular resistance, and worsening renal function, others have focused on the contribution of ADHF treatment to worsening renal function. In particular, loop diuretic therapy has been implicated in worsening renal function [8]. Furosemide administration has been associated with worsening pump function, increased filling pressures and increased neurohormonal and catecholamine release; however, this effect is transient [20]. Furosemide also appears to decrease GFR, an effect that appears to be mediated, at least in part, by adenosine release secondary to activation of the tubuloglomerular feedback mechanism in the kidney [21]. In fact, Eshaghian et al. [22] showed a dose-dependent association between furosemide administration and mortality in a large cohort of heart failure patients with severe systolic dysfunction. It is unclear, though, if this association reflects cause and effect or whether furosemide dosage is simply a marker of heart failure severity [22]. What is clear, however, is that treatment of ADHF with high-dose diuretics can result in decreased responsiveness to diuresis (resistance) or worsening renal function despite persistent hypervolemia. Decreased responsiveness to diuretics, the so-called braking phenomenon, results when increased sodium delivery to the proximal and distal nephron activates the tubuloglomerular feedback mechanism as the kidney attempts to regulate sodium handling. This results in activation of the RAAS and SNS, which, among other effects, causes distal tubular cell hypertrophy and increased sodium reabsorption, which ultimately counteracts the effects of loop diuretics [23]. Postdiuretic sodium avidity and increased proximal tubule reabsorption also likely contribute to diuretic resistance [24]. Additionally, adenosine release from the macula densa in response to increased sodium delivery results in afferent arteriolar vasoconstriction, which decreases GFR and renal blood flow and likely increases renal sodium avidity further. Increased proximal tubular sodium reabsorption is likely a luminal effect of adenosine $[25,26]$.

\section{Markers of Renal Dysfunction and AKI}

GFR is more sensitive than SCr in assessing renal function. However, in general practice, it is too burdensome to routinely calculate true GFR using inulin or some other exogenous marker. Provided it is not changing acutely, GFR can be estimated using SCr-based equations, including the Modification of Diet in Renal Disease (MDRD) equation or a simplified version (sMDRD). GFR can also be estimated using the Cockcroft-Gault equation. Creatinine clearance, a surrogate of GFR, can be calculated after a 24-hour urine collection. $\mathrm{SCr}$ alone can be deceiving, as one can have impaired renal function with a normal SCr, as it is dependent not only on renal function but also age, sex and muscle mass. Creatinine clearance and estimated GFR using the MDRD, sMDRD and Cockcroft-Gault equations were evaluated in a cohort of heart failure patients and validated against true GFR [27]. The equations all overestimated GFR at normal to near-normal renal function. They also underestimated GFR in severe renal dysfunction (GFR $<35 \mathrm{ml} / \mathrm{min}$ ) [11]. The predictive power of the formulas was strongest in the setting of severe heart failure. Estimated GFR using the MDRD equation was the most precise and had the best prognostic power for cardiovascular outcomes [27] (table 1). 
Cystatin C is a protease inhibitor produced by the body at a fairly constant rate. Unlike SCr, it is not affected by race, gender, age or body mass. It is freely filtered by the glomerulus and reabsorbed by the proximal tubule. It does not appear to be secreted into the urine. It has been proposed to be superior to $\mathrm{SCr}$ as a marker of renal function $[6,28,29]$. Further, it is an independent marker of adverse outcomes among patients with decompensated heart failure with a normal SCr [30].

Worsening renal function may be caused by intrinsic renal injury such as acute tubular necrosis from reduced renal blood flow. Changes in $\mathrm{SCr}$ are relatively insensitive and nonspecific for AKI. A consensus definition of AKI by the Acute Kidney Injury Network defines it as 'an abrupt (within 48 hours) reduction in kidney function currently defined as an absolute increase in serum creatinine of more than or equal to $0.3 \mathrm{mg} / \mathrm{dl}(\geq 26.4 \mu \mathrm{mol} / \mathrm{l})$, a percentage increase in serum creatinine of $\geq 50 \%$ (1.5fold from baseline), or a reduction in urine output (documented oliguria of less than $0.5 \mathrm{ml} / \mathrm{kg}$ per hour for more than six hours)' [31]. This definition corresponds to the term 'worsening renal function' in the heart failure literature. Novel biomarkers are being evaluated that may allow clinicians to detect AKI within hours of injury, allowing them to intervene early. It is unclear whether patients with heart failure and AKI, as opposed to chronic renal dysfunction or prerenal azotemia, may represent a subset of patients with renal dysfunction and a worse prognosis. One such biomarker being evaluated is neutrophil gelatinase-associated lipocalin (NGAL). Studies examining children receiving intravenous contrast and postcardiac surgery requiring cardiopulmonary bypass have shown serum and urinary NGAL measurements to be exquisitely sensitive and specific for detecting AKI within $2 \mathrm{~h}$ of injury $[32,33]$. Recently, investigators at Columbia University studied an assay for urinary NGAL to detect AKI. At the cutoff they used, urinary NGAL was $90 \%$ sensitive and $99.5 \%$ specific for detecting AKI. In contrast, it may take 1-3 days to detect AKI by a rise in SCr [34]. Damman et al. [35] studied urinary NGAL levels in 90 patients with chronic heart failure and 20 controls without heart failure. Those with chronic heart failure had significantly elevated urinary NGAL levels versus controls [175 (70-346) vs. 37 (6-58) $\mu \mathrm{g} / \mathrm{g} \mathrm{Cr,} \mathrm{p}<0.0001$ ] [35]. Another potential biomarker of AKI is kidney injury molecule 1, a marker of proximal tubular injury which, like NGAL, appears early in the urine in AKI and may help differentiate the type and site of injury [36, 37].

Further investigation is required to determine how these markers will help stratify patients admitted with
Table 1. The Cockcroft-Gault, MDRD and sMDRD formulas for calculating GFR [27]

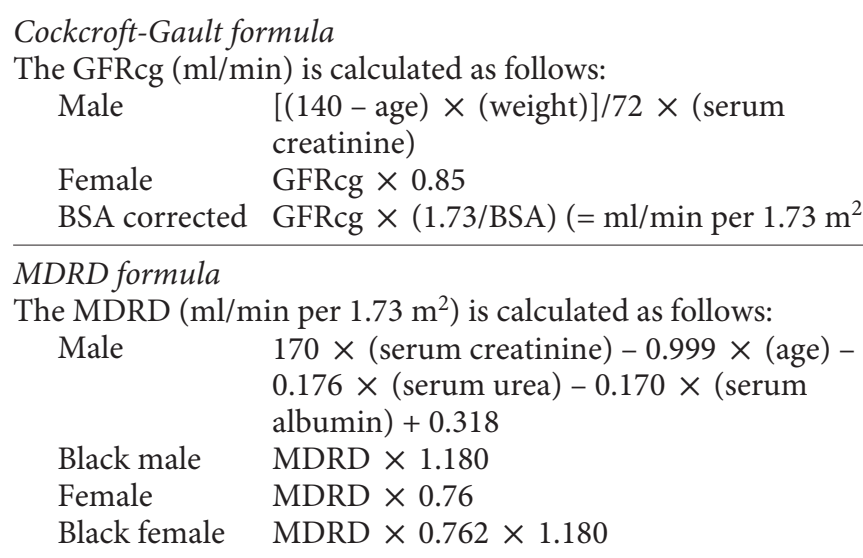

sMDRD formula

The sMDRD $\left(\mathrm{ml} / \mathrm{min}\right.$ per $\left.1.73 \mathrm{~m}^{2}\right)$ is calculated as follows:

Male $\quad 186.3 \times($ serum creatinine $)-1.154 \times$

(age) -0.203

Black male sMDRD $\times 1.212$

Female sMDRD $\times 0.742$

Black female $\quad$ sMDRD $\times 1.212 \times 0.742$

Reprinted from Smilde et al. [27], with permission. BSA = Body surface area.

ADHF according to risk. Potentially, these markers can help detect kidney injury earlier and help determine its location in the nephron. Furthermore, these markers can help determine the underlying etiology of worsening renal function. Together, this information may set the stage for investigation of timely and effective interventions to halt or mitigate kidney injury and thus improve the prognosis of patients admitted with ADHF.

\section{Treatment}

Several treatments have been proposed to treat ADHF while preserving renal function, to enhance diuresis and to correct worsening renal function. These include the addition of thiazide diuretics to counteract increased distal tubular sodium reabsorption, the addition of acetazolamide to treat increased proximal tubular sodium reabsorption, constant loop diuretic infusion, supraphysiologic doses of natriuretic peptides, vasopressin antagonists, adenosine receptor blockers and extracorporeal devices, including ultrafiltration and ventricular assist devices. 


\section{Treating Diuretic Resistance}

The addition of a thiazide diuretic, by acting on the distal tubule, can act synergistically with loop diuretics in the diuretic-resistant patient, inducing greater diuresis. Its effect on overall renal function and outcomes, however, is unclear [38]. Acetazolamide may improve diuresis by blocking proximal sodium reabsorption. It may also have additional benefits by improving central sleep apnea and correcting the metabolic alkalosis frequently encountered during diuresis [39]. Spironolactone and eplerenone are mild diuretics acting distally in the tubule which also have the additional benefit of attenuating the maladaptive neurohormonal response of the kidney to heart failure. They block the mineralocorticoid receptor, decreasing mortality in severe heart failure and attenuating the hypokalemic effects of aggressive diuresis [4042]. Finally, continuous loop diuretic infusion may be more effective than bolus loop diuretic administration by minimizing the effects of postdiuresis sodium avidity. This was initially demonstrated in a small study by Dormans et al. [43]. Diuretic infusion versus bolus therapy is currently under investigation in a larger multicenter NIH-funded study [44].

\section{Inotrope Therapy}

In severe ADHF characterized by low cardiac output, elevated systemic vascular resistance and hypotension, inotropes can maintain renal function and enhance diuresis by improving hemodynamics. So-called renaldose dopamine has been hypothesized to improve renal vascular hemodynamics through activation of the renal dopamine receptor. A recent study by Elkayam et al. [45] looked at the renal hemodynamic effects of dopamine in patients with chronic heart failure. This study on 13 patients demonstrated increased renal blood flow and decreased renal vascular resistance with escalating doses of dopamine (2-10 $\mu \mathrm{g} / \mathrm{kg} / \mathrm{min})$. Clinically, however, dopamine has not been shown to improve outcomes [45]. In general, while inotropes, including dopamine, dobutamine, milrinone and levosimendan, can improve shortterm hemodynamics and renal function, they have not been demonstrated to improve other outcomes such as mortality [46-49].

\section{Nesiritide}

Natriuretic peptides, including atrial natriuretic peptide and BNP, are released in response to myocardial stretch and serve to counterbalance the RAAS by increasing natriuresis, causing vasodilatation and suppressing the RAAS and SNS [23]. It has been postulated that di- uresis in the chronic heart failure patient may result in a rapid fall in the secretion of natriuretic peptides, thus resulting in decreased renal blood flow [9]. Therefore, recombinant BNP (nesiritide) was developed as a therapy to improve renal hemodynamics and enhance diuresis. Based on a pivotal trial published in 2000 by Colucci et al. [50], nesiritide was shown to lead to short-term improvement in symptoms and hemodynamics. Similar results were confirmed in a randomized trial of nesiritide versus nitroglycerin infusion, which led to its FDA approval [51]. Further investigation raised questions as to its efficacy and safety with regard to renal function [52, 53]. However, a larger prospective study of nesiritide in patients with renal dysfunction failed to show harm or benefit with respect to renal function in the treatment of ADHF [54]. In the large Follow-Up Serial Infusions Of Nesiritide (FUSION) II randomized trial of serial outpatient infusions of nesiritide versus placebo, there was no evidence of renal harm; however, the study failed to show a clinical benefit. However, the event rate of the primary end point was low in the FUSION II study, and it was therefore underpowered to detect a difference. There was, however, an increased incidence of hypotension in the nesiritide-treated group [55]. Interestingly, there is some evidence that nonhypotensive low-dose nesiritide may improve renal function in patients with ADHF, perhaps by preventing activation of the SNS and RAAS, thus avoiding their deleterious effects [56]. The Acute Study of Clinical Effectiveness of Nesiritide in Decompensated Heart Failure (ASCEND-HF) trial is a large, randomized, double-blind, multicentered trial of nesiritide versus placebo, currently enrolling patients admitted with ADHF. This trial will assess both symptoms and 30-day mortality and heart failure readmission [57].

\section{Vasopressin Antagonists}

As discussed earlier, nonosmotic release of vasopressin plays a role in the pathophysiology of heart failure, representing a maladaptive neurohormonal response. Vasopressin promotes free water retention through its activity on V2 receptors in the renal collecting tubules. Furthermore, it stimulates the V1 receptor, resulting in vasoconstriction. Theoretically, antagonism of vasopressin receptors could result in increased volume loss and correction of hyponatremia, which is an independent risk factor for poor outcome in heart failure, decrease cardiac afterload and perhaps have beneficial effects on cardiac hypertrophy $[14,58]$. Two vasopressin antagonists have been evaluated: conivaptan, an intravenous V1a and V2 receptor blocker, and tolvaptan, an oral selective V2 re- 
ceptor blocker. Initial excitement was generated by the Acute and Chronic Therapeutic Impact of a Vasopressin Antagonist in Congestive Heart Failure (ACTIV in CHF) study, which showed improvement in short-term weight loss without jeopardizing renal function or causing significant hypokalemia. A post hoc analysis of ACTIV in CHF suggested a reduction in 60-day mortality [59]. However, enthusiasm has been tempered by the larger Efficacy of Vasopressin Antagonism in Heart Failure Outcome Study With Tolvaptan (EVEREST) trial, which did not show a benefit with tolvaptan in a large cohort of patients admitted with ADHF and systolic dysfunction in regard to mortality or heart failure readmission. It appeared to be safe, however, with no significant worsening of renal function. It remains to be seen whether there is a role for tolvaptan in the treatment of patients with ADHF complicated by hyponatremia and/or renal dysfunction $[60,61]$.

\section{Adenosine Receptor Antagonists}

As previously discussed, renal tubuloglomerular feedback is a normal homeostatic mechanism in the kidney to maintain electrolyte and fluid balance, triggered by increased sodium delivery to the distal nephron. In the setting of heart failure and attempted diuresis, however, this mechanism becomes maladaptive, resulting in diuretic resistance and contributing to decreased GFR. Adenosine appears to mediate these effects by causing afferent arteriolar vasoconstriction and increased proximal tubular sodium reabsorption [26, 62]. There are multiple adenosine receptor subtypes throughout the body's various tissues. The tubuloglomerular feedback mechanism is mediated through the adenosine receptor subtype 1 (A1). A1 antagonists attenuate furosemide's propensity to reduce GFR and facilitate urine output [21]. Givertz et al. [25] recently reported the results of two phase II protocols studying the A1 antagonist KW-3902. One protocol looked at 146 patients admitted with ADHF and renal insufficiency. The second protocol looked at a sicker population of NYHA class III or IV patients who were hospitalized and classified as 'diuretic resistant'. Both protocols confirmed the potential utility of adenosine receptor blockers in enhancing diuresis, reducing loop diuretic requirements and preserving renal function. In the ADHF protocol, the study drug increased urine output over the first $6 \mathrm{~h}$, and SCr had decreased in all the study drug groups versus placebo at day 2. Early discontinuation of treatment for adequate diuresis was reported in $30 \%$ of study drug-treated patients and $4 \%$ of placebo-treated patients. Adverse events were similar in both groups [25].
Larger phase III trials, namely A Study of the Selective A1 Adenosine Receptor Antagonist KW-3902 for Patients Hospitalized With Acute HF and Volume Overload to Assess Treatment Effect on Congestion and Renal Function 1 and 2 (PROTECT-1 and PROTECT-2), are currently enrolling patients with ADHF and renal insufficiency and will provide more definitive data on the safety and efficacy of the selective adenosine A1 receptor blocker KW-3902 [63, 64].

\section{Ultrafiltration}

Extracorporeal methods of volume removal have sparked interest among cardiologists with the advent of small, relatively easy to use devices for ultrafiltration. The benefits of these devices include overcoming diuretic resistance, rapid volume removal and increased sodium removal relative to diuretics. In addition, isoosmotic fluid removal will not result in increased sodium delivery to the distal nephron and resultant activation of the tubuloglomerular feedback mechanism as can occur with loop diuretics. Theoretically, this will result in less activation of the maladaptive RAAS and SNS responses. Finally, there is less risk of hypokalemia and resultant arrhythmias. Marenzi et al. [65] performed a small study looking at the hemodynamic consequences of ultrafiltration. The patients all had NYHA class IV symptoms and large diuretic requirements. On average, they lost 4 liters of fluid over a mean time period of $9 \mathrm{~h}$ by ultrafiltration and experienced relief of symptoms with a concomitant decrease in right atrial pressure and pulmonary wedge pressure. The cardiac output improved and the mean systemic arterial pressure remained stable. Additionally, their diuretic requirement decreased [65]. In 2005, a feasibility study was published using a small, easier to use device, which was positive [66]. The Ultrafiltration versus Intravenous Diuretics for Patients Hospitalized for Acute Decompensated Heart Failure (UNLOAD) study was published in 2007. This study randomized 200 patients admitted to the hospital with volume overload to either ultrafiltration or intravenous diuretic therapy. The primary efficacy end points were weight loss at $48 \mathrm{~h}$, which was significantly greater in the ultrafiltration group, and dyspnea scores, which were not different between the two groups. There was no difference between the two groups in terms of worsening renal function. In terms of secondary end points, length of index hospitalization, Living with Heart Failure scores, BNP levels and 6-min walk distance were all similar. At 90 days, however, heart failure rehospitalizations, rehospitalization days per patient and unscheduled clinic or emergency department visits 
were all significantly decreased. Thus, the UNLOAD trial confirmed the clinical safety of ultrafiltration, but there was a disconnect between the increased weight loss and clinical symptoms. It is also puzzling that although there was increased volume removal, the length of stay for the index hospitalization was not different between the groups. The investigators point out, however, that the long-term benefit, i.e. reduced rehospitalization for heart failure at 90 days, may reflect increased sodium removal and decreased diuretic requirement in the ultrafiltration group [67]. The Cardiorenal Rescue Study in Acute Decompensated Heart Failure (CARRESS-HF) trial, now underway, will examine the utility of ultrafiltration in a population of patients admitted with ADHF and concomitant CRS defined as baseline renal insufficiency or worsening renal function with treatment. The primary end points are change in creatinine and change in weight at $96 \mathrm{~h}$. The hypothesis is that correcting congestion without the deleterious effects of diuretics will improve renal perfusion and GFR [68].

\section{Comments}

Clearly, heart failure complicated by CRS is a significant problem. We know that patients with heart failure and chronic renal insufficiency or ADHF and worsening renal function are at substantial risk for poor outcomes. Understanding the underlying pathophysiology of the CRS will require further research. This research is important in order to identify therapeutic strategies target- ed at the underlying pathologic mechanisms which we hope will ultimately benefit patients. Some therapeutic strategies already developed have been disappointing. Inotrope therapy, for example, should target the hemodynamic abnormalities which can lead to worsening renal function. However, large trials have shown this strategy to be deleterious. Similarly, nesiritide would be expected to improve renal function by opposing the maladaptive RAAS and reducing vascular resistance in the kidney. However, while larger studies have shown some improvement in hemodynamic variables, long-term outcomes have been unremarkable and, indeed, there has been some suggestion of harm. Ultrafiltration has been shown to significantly increase volume loss in ADHF, but significant long-term benefit was not proven. The lesson from these experiences is that short-term changes in hemodynamic variables do not necessarily translate into beneficial short- or long-term outcomes. Adenosine A1 receptor antagonists are currently being evaluated for treatment of heart failure in the setting of renal dysfunction and show promise. However, this must be tempered by the recognition that we must await results of the larger, randomized, controlled trails before we can reach conclusions about safety and efficacy.

As further research progresses, including integration of novel biomarkers to further stratify subsets of heart failure patients with CRS, we hope to develop further effective therapies that target the underlying mechanism of this difficult disease process in order to better treat the ever-growing heart failure population.

\section{References}

1 Rosamond W, Flegal K, Furie K, Go A, Greenlund K, Haase N, Hailpern SM, Ho M, Howard V, Kissela B, Kittner S, Lloyd-Jones D, McDermott M, Meigs J, Moy C, Nichol G, O'Donnell C, Roger V, Sorlie P, Steinberger J, Thom T, Wilson M, Hong Y; American Heart Association Statistics Committee and Stroke Statistics Subcommittee: Heart disease and stroke statistics - 2008 update: a report from the American Heart Association Statistics Committee and Stroke Statistics Subcommittee. Circulation 2008;117:e25e146.

2 Heywood JT: The cardiorenal syndrome: lessons from the ADHERE database and treatment options. Heart Fail Rev 2004;9:195201.

\footnotetext{
3 Ronco C, Haapio M, House A A, Anavekar N Bellomo R: Cardiorenal syndrome. J Am Coll Cardiol 2008;52:1527-1539.

4 Dries DL, Exner DV, Domanski MJ, Greenberg B, Stevenson LW: The prognostic implications of renal insufficiency in asymptomatic and symptomatic patients with left ventricular systolic dysfunction. J Am Coll Cardiol 2000;35:681-689.

5 Hillege HL, Nitsch D, Pfeffer MA, Swedberg K, McMurray JJ, Yusuf S, Granger CB, Michelson EL, Ostergren J, Cornel JH, de Zeeuw D, Pocock S, van Veldhuisen DJ; Candesartan in Heart Failure: Assessment of Reduction in Mortality and Morbidity (CHARM) Investigators: Renal function as a predictor of outcome in a broad spectrum of patients with heart failure. Circulation 2006;113: 671-678.
}

\footnotetext{
6 Smith GL, Lichtman JH, Bracken MB, Shlipak MG, Phillips CO, DiCapua P, Krumholz HM: Renal impairment and outcomes in heart failure: systematic review and metaanalysis. J Am Coll Cardiol 2006;47:19871996.

7 Forman DE, Butler J, Wang Y, Abraham WT, O'Connor CM, Gottlieb SS, Loh E, Massie BM, Rich MW, Stevenson LW, Young JB, Krumholz HM: Incidence, predictors at admission, and impact of worsening renal function among patients hospitalized with heart failure. J Am Coll Cardiol 2004;43:6167.
} 
-8 Butler J, Forman DE, Abraham WT, Gottlieb SS, Loh E, Massie BM, O’Connor CM, Rich MW, Stevenson LW, Wang Y, Young JB, Krumholz HM: Relationship between heart failure treatment and development of worsening renal function among hospitalized patients. Am Heart J 2004;147:331-338.

-9 Weinfeld MS, Chertow GM, Stevenson LW: Aggravated renal dysfunction during intensive therapy for advanced chronic heart failure. Am Heart J 1999;138:285-290.

-10 Nohria A, Hasselblad V, Stebbins A, Pauly DF, Fonarow GC, Shah M, Yancy CW, Califf RM, Stevenson LW, Hill JA: Cardiorenal interactions: insights from the ESCAPE trial. J Am Coll Cardiol 2008;51:1268-1274.

11 Schrier RW, Abraham WT: Hormones and hemodynamics in heart failure. $\mathrm{N}$ Engl J Med 1999;341:577-585.

-12 Ferguson DW, Berg WJ, Roach PJ, Oren RM, Mark AL: Effects of heart failure on baroreflex control of sympathetic neural activity. Am J Cardiol 1992;69:523-531.

13 Weber KT: Aldosterone in congestive heart failure. N Engl J Med 2001;345:1689-1697.

14 Schrier RW: Role of diminished renal function in cardiovascular mortality: marker or pathogenetic factor? J Am Coll Cardiol 2006; 47:1-8.

-15 Bongartz LG, Cramer MJ, Doevendans PA, Joles JA, Braam B: The severe cardiorenal syndrome: 'Guyton revisited'. Eur Heart J 2005;26:11-17.

16 Levin A: Kidneys, hearts, hormones and immunomodulators: integrated understandings. Blood Purif 2006;24:46-50.

-17 Virani SA: Management of acute decompensated heart failure: renal implications. Blood Purif 2008;26:18-22.

-18 Butler J, Geisberg C, Howser R, Portner PM, Rogers JG, Deng MC, Pierson RN 3rd: Relationship between renal function and left ventricular assist device use. Ann Thorac Surg 2006;81:1745-1751.

-19 Mullens W, Abrahams Z, Skouri HN, Francis GS, Taylor DO, Starling RC, Paganini E, Tang WH: Elevated intra-abdominal pressure in acute decompensated heart failure: a potential contributor to worsening renal function? J Am Coll Cardiol 2008;51:300306.

20 Francis GS, Siegel RM, Goldsmith SR, Olivari MT, Levine TB, Cohn JN: Acute vasoconstrictor response to intravenous furosemide in patients with chronic congestive heart failure. Activation of the neurohumoral axis. Ann Intern Med 1985;103:1-6.

-21 Gottlieb SS, Brater DC, Thomas I, Havranek E, Bourge R, Goldman S, Dyer F, Gomez M, Bennett D, Ticho B, Beckman E, Abraham WT: BG9719 (CVT-124), an A1 adenosine receptor antagonist, protects against the decline in renal function observed with diuretic therapy. Circulation 2002;105:1348-1353.
22 Eshaghian S, Horwich TB, Fonarow GC: Relation of loop diuretic dose to mortality in advanced heart failure. Am J Cardiol 2006; 97:1759-1764.

23 Kazory A, Ross EA: Contemporary trends in the pharmacological and extracorporeal management of heart failure: a nephrologic perspective. Circulation 2008;117:975-983.

24 Wittstein IS: Diuretics; in Baughman KL, Baumgartner WA (eds): Treatment of Advanced Heart Disease. New York, Taylor and Francis, 2006, pp 83-84.

25 Givertz MM, Massie BM, Fields TK, Pearson LL, Dittrich HC; CKI-201 and CKI-202 Investigators: The effects of KW-3902, an adenosine A1-receptor antagonist, on diuresis and renal function in patients with acute decompensated heart failure and renal impairment or diuretic resistance. J Am Coll Cardiol 2007;50:1551-1560.

26 Rajaram V, Joseph J: Role of adenosine antagonism in the cardio-renal syndrome: pathophysiology and therapeutic potential. Curr Heart Fail Rep 2007;4:153-157.

27 Smilde TD, van Veldhuisen DJ, Navis G, Voors AA, Hillege HL: Drawbacks and prognostic value of formulas estimating renal function in patients with chronic heart failure and systolic dysfunction. Circulation 2006;114:1572-1580.

28 Koyner JL, Bennett MR, Worcester EM, Ma Q, Raman J, Jeevanandam V, Kasza KE, O’Connor MF, Konczal DJ, Trevino S, Devarajan P, Murray PT: Urinary cystatin C as an early biomarker of acute kidney injury following adult cardiothoracic surgery. Kidney Int 2008;74:1059-1069.

-29 Shlipak MG, Sarnak MJ, Katz R, Fried LF, Seliger SL, Newman AB, Siscovick DS, Stehman-Breen C: Cystatin C and the risk of death and cardiovascular events among elderly persons. N Engl J Med 2005;352:2049_ 2060.

30 Lassus J, Harjola VP, Sund R, Siirilä-Waris K, Melin J, Peuhkurinen K, Pulkki K, Nieminen MS; for the FINN-AKVA Study group: Prognostic value of cystatin $\mathrm{C}$ in acute heart failure in relation to other markers of renal function and NT-proBNP. Eur Heart J 2007; 28:1841-1847.

-31 Mehta RL, Kellum JA, Shah SV, Molitoris BA, Ronco C, Warnock DG, Levin A; Acute Kidney Injury Network: Acute Kidney Injury Network: report of an initiative to improve outcomes in acute kidney injury. Crit Care 2007;11:R31.

-32 Hirsch R, Dent C, Pfriem H, Allen J, Beekman RH 3rd, Ma Q, Dastrala S, Bennett M, Mitsnefes M, Devarajan P: NGAL is an early predictive biomarker of contrast-induced nephropathy in children. Pediatr Nephrol 2007;22:2089-2095.
33 Mishra J, Dent C, Tarabishi R, Mitsnefes MM, Ma Q, Kelly C, Ruff SM, Zahedi K, Shao M, Bean J, Mori K, Barasch J, Devarajan P: Neutrophil gelatinase-associated lipocalin (NGAL) as a biomarker for acute renal injury after cardiac surgery. Lancet 2005;365:12311238.

>34 Nickolas TL, O’Rourke MJ, Yang J, Sise ME, Canetta PA, Barasch N, Buchen C, Khan F, Mori K, Giglio J, Devarajan P, Barasch J: Sensitivity and specificity of a single emergency department measurement of urinary neutrophil gelatinase-associated lipocalin for diagnosing acute kidney injury. Ann Intern Med 2008;148:810-819.

35 Damman K, van Veldhuisen DJ, Navis G, Voors AA, Hillege HL: Urinary neutrophil gelatinase associated lipocalin (NGAL), a marker of tubular damage, is increased in patients with chronic heart failure. Eur J Heart Fail 2008;10:997-1000.

36 Bonventre JV: Kidney Injury Molecule-1 (KIM-1): a specific and sensitive biomarker of kidney injury. Scand J Clin Lab Invest Suppl 2008;241:78-83.

37 Han WK, Waikar SS, Johnson A, Betensky RA, Dent CL, Devarajan P, Bonventre JV: Urinary biomarkers in the early diagnosis of acute kidney injury. Kidney Int 2008;73: 863-869.

38 Channer KS, McLean KA, Lawson-Matthew $\mathrm{P}$, Richardson $\mathrm{M}$ : Combination diuretic treatment in severe heart failure: a randomised controlled trial. Br Heart J 1994;71: 146-150.

-39 Javaheri S: Acetazolamide improves central sleep apnea in heart failure: a double-blind, prospective study. Am J Respir Crit Care Med 2006;173:234-237.

40 Domanski M, Norman J, Pitt B, Haigney M, Hanlon S, Peyster E; Studies of Left Ventricular Dysfunction: Diuretic use, progressive heart failure, and death in patients in the Studies Of Left Ventricular Dysfunction (SOLVD). J Am Coll Cardiol 2003;42:705708.

41 Pitt B, Remme W, Zannad F, Neaton J, Martinez F, Roniker B, Bittman R, Hurley S, Kleiman J, Gatlin M; Eplerenone Post-Acute Myocardial Infarction Heart Failure Efficacy and Survival Study Investigators: Eplerenone, a selective aldosterone blocker, in patients with left ventricular dysfunction after myocardial infarction. N Engl J Med 2003; 348:1309-1321.

42 Pitt B, Zannad F, Remme WJ, Cody R, Castaigne A, Perez A, Palensky J, Wittes J: The effect of spironolactone on morbidity and mortality in patients with severe heart failure. Randomized Aldactone Evaluation Study Investigators. N Engl J Med 1999;341: 709-717.

-43 Dormans TP, van Meyel JJ, Gerlag PG, Tan Y, Russel FG, Smits P: Diuretic efficacy of high dose furosemide in severe heart failure: bolus injection versus continuous infusion. J Am Coll Cardiol 1996;28:376-382. 
44 Determining Optimal Dose and Duration of Diuretic Treatment in People With Acute Heart Failure (The DOSE-AHF Study). http://clinicaltrials.gov/ct2/show/NCT0057 7135? term $=$ dose+furosemide\&rank $=1 \quad$ (accessed 2008)

45 Elkayam U, Ng TM, Hatamizadeh P, Janmohamed M, Mehra A: Renal vasodilatory action of dopamine in patients with heart failure: magnitude of effect and site of action. Circulation 2008;117:200-205

-46 Mebazaa A, Nieminen MS, Packer M, Cohen-Solal A, Kleber FX, Pocock SJ, Thakkar R, Padley RJ, Põder P, Kivikko M; SURVIVE Investigators: Levosimendan vs dobutamine for patients with acute decompensated heart failure: the SURVIVE Randomized Trial. JAMA 2007;297:1883-1891.

-47 Cuffe MS, Califf RM, Adams KF Jr, Benza R, Bourge R, Colucci WS, Massie BM, O'Connor CM, Pina I, Quigg R, Silver MA, Gheorghiade M; Outcomes of a Prospective Trial of Intravenous Milrinone for Exacerbations of Chronic Heart Failure (OPTIME-CHF) Investigators: Short-term intravenous milrinone for acute exacerbation of chronic heart failure: a randomized controlled trial. JAMA 2002;287:1541-1547.

-48 Felker GM, O’Connor CM: Inotropic therapy for heart failure: an evidence-based approach. Am Heart J 2001;142:393-401.

-49 Packer M, Carver JR, Rodeheffer RJ, Rodeheffer RJ, Ivanhoe RJ, DiBianco R, Zeldis SM, Hendrix GH, Bommer WJ, Elkayam U, Kukin ML, et al: Effect of oral milrinone on mortality in severe chronic heart failure. The PROMISE Study Research Group. N Engl J Med 1991;325:1468-1475.

-50 Colucci WS, Elkayam U, Horton DP, Abraham WT, Bourge RC, Johnson AD, Wagoner LE, Givertz MM, Liang CS, Neibaur M, Haught WH, LeJemtel TH: Intravenous nesiritide, a natriuretic peptide, in the treatment of decompensated congestive heart failure. Nesiritide Study Group. N Engl J Med 2000;343:246-253.

51 Publication Committee for the VMAC Investigators (Vasodilatation in the Management of Acute CHF): Intravenous nesiritide vs nitroglycerin for treatment of decompensated congestive heart failure: a randomized controlled trial. JAMA 2002;287:1531-1540.

- 52 Sackner-Bernstein JD, Skopicki HA, Aaronson KD: Risk of worsening renal function with nesiritide in patients with acutely decompensated heart failure. Circulation 2005; 111:1487-1491.
53 Wang DJ, Dowling TC, Meadows D, Ayala T, Marshall J, Minshall S, Greenberg N, Thattassery E, Fisher ML, Rao K, Gottlieb SS: Nesiritide does not improve renal function in patients with chronic heart failure and worsening serum creatinine. Circulation 2004; 110:1620-1625.

54 Witteles RM, Kao D, Christopherson D, Matsuda K, Vagelos RH, Schreiber D, Fowler MB: Impact of nesiritide on renal function in patients with acute decompensated heart failure and pre-existing renal dysfunction. A randomized, double-blind, placebo-controlled clinical trial. J Am Coll Cardiol 2007; 50:1835-1840.

55 Yancy CW, Krum H, Massie BM, Silver MA, Stevenson LW, Cheng M, Kim SS, Evans R, for the FUSION II Investigators: Safety and efficacy of outpatient nesiritide in patients with advanced heart failure. Results of the second Follow-Up Serial Infusions Of Nesiritide (FUSION II) trial. Circ Heart Fail 2008;1:9-16.

56 Riter HG, Redfield MM, Burnett JC, Chen $\mathrm{HH}$ : Nonhypotensive low-dose nesiritide has differential renal effects compared with standard-dose nesiritide in patients with acute decompensated heart failure and renal dysfunction. J Am Coll Cardiol 2006;47: 2334-2335.

57 Acute Study of Clinical Effectiveness of Nesiritide in Decompensated Heart Failure. http://clinicaltrials.gov/ct2/show/NCT0047 5852? term $=$ ascend + nesiritide $\&$ rank $=1 \quad$ (accessed 2008).

58 Klein L, O'Connor CM, Leimberger JD, Gattis-Stough W, Piña IL, Felker GM, Adams KF Jr, Califf RM, Gheorghiade M; OPTIMECHF Investigators: Lower serum sodium is associated with increased short-term mortality in hospitalized patients with worsening heart failure: results from the Outcomes of a Prospective Trial of Intravenous Milrinone for Exacerbations of Chronic Heart Failure (OPTIME-CHF) study. Circulation 2005;111:2454-2460.

59 Gheorghiade M, Gattis WA, O'Connor CM, Adams KF Jr, Elkayam U, Barbagelata A, Ghali JK, Benza RL, McGrew FA, Klapholz M, Ouyang J, Orlandi C; Acute and Chronic Therapeutic Impact of a Vasopressin Antagonist in Congestive Heart Failure (ACTIV in CHF) Investigators: Effects of tolvaptan, a vasopressin antagonist, in patients hospitalized with worsening heart failure: a randomized controlled trial. JAMA 2004;291:19631971.

-60 Gheorghiade M, Konstam MA, Burnett JC Jr, Grinfeld L, Maggioni AP, Swedberg K, Udelson JE, Zannad F, Cook T, Ouyang J, Zimmer C, Orlandi C; Efficacy of Vasopressin Antagonism in Heart Failure Outcome Study With Tolvaptan (EVEREST) Investigators: Shortterm clinical effects of tolvaptan, an oral vasopressin antagonist, in patients hospitalized for heart failure: the EVEREST Clinica Status Trials. JAMA 2007;297:1332-1343.
61 Konstam MA, Gheorghiade M, Burnett JC Jr, Grinfeld L, Maggioni AP, Swedberg K, Udelson JE, Zannad F, Cook T, Ouyang J, Zimmer C, Orlandi C; Efficacy of Vasopressin Antagonism in Heart Failure Outcome Study With Tolvaptan (EVEREST) Investigators: Effects of oral tolvaptan in patients hospitalized for worsening heart failure: the EVEREST Outcome Trial. JAMA 2007;297:1319-1331.

-62 Elkayam U, Mehra A, Cohen G, Tummala PP, Karaalp IS, Wani OR, Canetti M: Renal circulatory effects of adenosine in patients with chronic heart failure. J Am Coll Cardiol 1998:32:211-215.

63 PROTECT-2: A Study of the Selective A1 Adenosine Receptor Antagonist KW-3902 for Patients Hospitalized With Acute HF and Volume Overload to Assess Treatment Effect on Congestion and Renal Function. http:// clinicaltrials.gov/ct2/show/NCT00354458? term=PROTECT\&rank=38 (accessed 2008).

64 PROTECT-1: A Study of the Selective A1 Adenosine Receptor Antagonist KW-3902 for Patients Hospitalized With Acute HF and Volume Overload to Assess Treatment Effect on Congestion and Renal Function. http:// clinicaltrials.gov/ct2/show/NCT00328692? term=PROTECT\&rank=39 (accessed 2008).

65 Marenzi G, Lauri G, Grazi M, Assanelli E, Campodonico J, Agostoni P: Circulatory response to fluid overload removal by extracorporeal ultrafiltration in refractory congestive heart failure. J Am Coll Cardiol 2001; 38:963-968.

66 Bart BA, Boyle A, Bank AJ, Anand I, Olivari MT, Kraemer M, Mackedanz S, Sobotka PA, Schollmeyer M, Goldsmith SR: Ultrafiltration versus usual care for hospitalized patients with heart failure: the Relief for Acutely Fluid-Overloaded Patients With Decompensated Congestive Heart Failure (RAPIDCHF) trial. J Am Coll Cardiol 2005;46: 2043-2046.

67 Costanzo MR, Guglin ME, Saltzberg MT, Jessup ML, Bart BA, Teerlink JR, Jaski BE, Fang JC, Feller ED, Haas GJ, Anderson AS, Schollmeyer MP, Sobotka PA; UNLOAD Trial Investigators: Ultrafiltration versus intravenous diuretics for patients hospitalized for acute decompensated heart failure. J Am Coll Cardiol 2007;49:675-683.

68 Effectiveness of Ultrafiltration in Treating People With Acute Decompensated Heart Failure and Cardiorenal Syndrome (The CARRESS Study). http://clinicaltrials.gov/ ct $2 /$ show/NCT00608491? term $=$ carress \& rank=1 (accessed 2008). 